\title{
PERFORMANCES DA CULTURA VISUAL E DE EVENTOS NO PROCESSO \\ DE REVITALIZAÇÃO URBANA NO "DISTRITO CRIATIVO" DE \\ PORTO ALEGRE
}

\author{
Roberta Simon ${ }^{1}$
}

\section{Etnografias da e na cidade}

Este artigo é fruto de reflexões geradas durante sua apresentação na $29^{\mathrm{a}}$ Reunião Brasileira de Antropologia, realizada entre os dias 03 e 06 de agosto de 2014, em Natal/RN. Busco com esta pesquisa compreender como são construídos os processos de visibilização por meio da cultura visual e da experiência estética de eventos exploratórios a partir de um estudo etnográfico realizados pelo "Distrito Criativo", mais especificamente ocorridos no bairro Floresta, em Porto Alegre, RS, Brasil. Em uma tarde ensolarada no final do mês de agosto de 2013, mais de quarenta pessoas se reuniram por três horas para percorrer as ruas e quarteirões, guiadas por Jorge Piqué, um dos fundadores da Agência de Inovação Social UrbsNova. Incentivada por pesquisas desenvolvidas no Núcleo de Antropologia Visual (Navisual), da Universidade Federal do Rio Grande do Sul, e motivada pelas relações entre imagem, comunicação, cultura e cidade, fui adentrando e me envolvendo com o campo.

Após esta primeira experiência exploratória pelo bairro, foi realizada, na manhã do primeiro sábado de outubro de 2013, uma segunda e última edição de caráter exploratório e experimental, realizado no âmbito de ações de inovação social pela UrbsNova. Esta, criou o projeto mais amplo, chamado "Distrito Criativo" e desenvolveu uma ação com saídas permanentes: os "Passeio das Artes", o qual percorre empreendimentos de economia criativa ligados ou de interesse ao projeto. Participei da edição-teste, na última tarde de maio de 2014, e de outra, aberta ao público em geral, em outubro. No intervalo entre esses eventos, etnografei dois encontros do grupo Porto Alegre CITE ("Cidadãos, Inovação, Tecnologia, Empreendorismo"), realizados no espaço Nós Coworking e organizados por Walker Massa, em que indivíduos da comunidade (inclusive muitos arquitetos e estudantes de arquitetura) e instituições internacionais interessadas se reúnem para refletir sobre os processos políticos, econômicos e sociais da cidade.

Provoquei algumas incursões ao bairro à la Michel de Certeau (1994) ${ }^{2}$, para observar as dinâmicas da feira hortifrúti, que ocorrem sempre às terças-feiras, e do

\footnotetext{
${ }^{1}$ Universidade Federal do Rio Grande do Sul; Brasil
} 
brechó de rua, que há praticamente um ano ocorria todos os sábados, mas a partir de outubro de 2014, vão diminuir a periodicidade, pois, segundo a principal organizadora do brechó, D. Helena, as vendas não estão conforme o esperado. Segundo ela, as pessoas veem, olham, acham tudo bonito, mas dificilmente compram. Esta decisão de diminuírem a frequência do brechó (uma atividade com iniciativa da Associação Refloresta e apoio do Porto Alegre Hostel Boutique), junto a outras resistências por parte dos trabalhadores da região (conforme relata o organizador da UrbsNova), acabam por suscitar reflexões e atualizações dos planos de revitalização urbana desenvolvidos pelas entidades.

Adentrei ao campo por participar do Navisual, o qual desenvolve pesquisas nas áreas da antropologia urbana e visual. Colaborei com o projeto "Porto Alegre da Copa, os ritmos de construção destrutiva ou destruição construtiva: oficina de etnografia audiovisual no Navisual, 2013 e 2014", cujo objetivo foi desenvolver oficinas de formação em pesquisa com suportes audiovisuais que contribuíssem para reflexões sobre as transformações urbanas geradas em prol do megaevento esportivo da Copa do Mundo 2014. Para tanto, realizamos saídas de campo por pontos específicos de Porto Alegre, registrando imagética e áudio-visualmente as metamorfoses da cidade. Estas, ganham novas perspectivas pelas lentes das câmeras. O processo de captura dessas dialéticas das durações (Bachelard, 1988) revelam narrativas imagéticas e novas compreensões sobre as dinâmicas das grandes metrópoles, com suas complexidades de acontecimentos e acasos.

Com abordagens teórico-conceituais do campo antropológico e da etnografia de rua, somos estimulados à produção de diferentes imagens no e do meio urbano a partir de categorias conceituais, instituídas pelo Banco de Imagens e Efeitos Visuais (BIEV). A primeira interrogação que se coloca na etnografia de rua com registro visual, é: "tirar fotografia do quê?". Sempre que voltamos à campo o questionamento ressurge, o direcionamento se refaz, os roteiros e conceitos são revistos. Buscamos seguir o roteiro planejado ao mesmo tempo em que estamos abertos para as subjetividades e possibilidades que a própria experiência nos provoca e que podem, inclusive,

\footnotetext{
2 Para o autor, o ato de caminhar "a passos perdidos" seria uma forma de narrar a cidade organizando um conjunto de possibilidades e experiências vividas pelo sujeito. Há uma ideia de espaço urbano em constante transformação que é, então, registrada, pensada, articulada com diferentes saberes e fazeres. Um espaço em que habitantes e frequentadores afetam e são afetados, coexistem e inexistem, atravessam tempos-espaços construindo e destruindo, sempre em movimento.
} 
influenciar nossos objetos de estudo. Segundo Elisa Lipkau (2007), nesse campo criativo de experimentação, o processo etnográfico de representação visual age como um meio de comunicação que catalisa e performatiza novas produções sociais. Como um terceiro olhar ou uma terceira voz, o processo ritualístico de interação do pesquisador com o campo se caracteriza por reunir diferentes visões e perspectivas. Tanto o etnógrafo, quanto o sujeito e seu entorno passam por processos de transformação e criação de novas representações.

Na condição de aprendiz de antropóloga, estas transformações são percebidas com mais intensidade. Quanto aos fundamentos antropológicos, ganha destaque a demanda por um exercício constante de vigilância e ruptura epistemológica, como nos alerta Gaston Bachelard (1996) e por um estranhamento do familiar, segundo afirma Roberto Da Matta (apud Velho, 1978). O campo é o laboratório de experimentações e desafios. Com a recorrência de saídas e o exercício posterior da escrita, tornou-se mais nítida a importância das notas e dos diários de campo como peças fundamentais para "pensar os caminhos e obstáculos epistemológicos que transformam uma intenção de pesquisa em Antropologia em um objeto de estudo orientado pelos conceitos do campo da Antropologia" (Guterres, apud Eckert e Rocha, 2013b: 260).

A etnografia de rua alia-se a outras técnicas e métodos possíveis para narrar as cidades e suas múltiplas formas de interação, considerando a fluidez e a complexidade das sociedades urbanas. Na etnografia de rua há uma

preocupação com os arranjos estéticos assumidos pelos habitantes em suas sociabilidades, nas ocupações da rua, nos percursos e itinerários no interior da cidade. A vida cotidiana de uma cidade, sob esta perspectiva estética, é moldada na própria ação dos sujeitos, no depósito das camadas de tempo que estas ações, repetidas dia a dia conformam" (Eckert e Rocha, 2013a: 14).

Em busca de captar tais subjetividades, estéticas e camadas de tempo, o grupo do Navisual, foi a campo com câmeras fotográficas e videográficas. Pelo site de relacionamentos Facebook, alguns integrantes receberam o convite e estenderam aos demais para participar da primeira edição da "Expedição Floresta". Organizamos as necessidades de equipamentos e a distribuição das tarefas, ficando com a coordenadora a captura audiovisual com uma câmera filmadora, e a captura fotográfica com os demais. Era minha primeira experiência de etnografia de rua e visual e, hoje, percebo que a preocupação com o registro das imagens se sobrepôs ao registro textual, pois não 
fiz muitas notas de campo. Considerando a abertura narrativa que as imagens nos proporcionam, o alargamento do ângulo de visão e um aumento na capacidade de memorização visual (Conord, 2013: 23), pensava que as imagens seriam suficientes. Este é o grande perigo das imagens, a grande armadilha, e precisamos, enquanto pesquisadores, ficar vigilantes para alinhar sistematicamente os diários de campo textual e visual.

As fotografias possuem o poder mágico de fazer crer que guardam todos os tesouros do momento e os pormenores das histórias. O uso das imagens como fonte de arquivo para os cientistas possui múltiplas contribuições. Jean Brunhes quando "descrevia as paisagens com a ajuda da imagem fixa, [...] detalhava as cores, as linhas, as texturas. Para realizar um tipo de inventário fotográfico dos espaços, seu método compreendia a vista direta, o registro foto e a pesquisa oral" (Conord, 2013: 16). A etnografia compreende uma múltipla articulação de técnicas e estas produzem diferentes resultados tanto na forma, quanto no conteúdo. Quando Reinhardt (2004) nos propõe uma reflexão acerca do fazer etnográfico em sua dimensão escritural a partir de Derrida, Lévis-Strauss e James Clifford, afirma que a escritura é "uma substância autêntica de um modelo comunicativo" (ibidem: 251) e "a etnografia nada mais é do que encenação da passagem da oralidade para a escritura" (ibidem: 252). Essa passagem das oralidades gravadas pela memória para o texto escrito, recebe dinâmicas de estilo e conteúdo diferenciadas se nesse processo recorremos aos registros audiovisuais, fotográficos e/ou bloco de notas realizados em campo.

Do nosso grupo, participaram da primeira edição da "Expedição Floresta" a professora Cornelia Eckert (coordenadora Navisual/UFRGS), os pesquisadores Fabiela Bigossi (então pós-doutoranda em Antropologia/UFRGS), Victoria (graduanda em Ciências Sociais/UFRGS e então bolsista do Navisual), Yuri Rapkiewicz (graduando em Ciências Sociais/UFRGS), Fabricio Barreto (fotógrafo e pesquisador voluntário), Cedric Benet (videomaker e pesquisador voluntário) e eu (comunicadora social e pesquisadora voluntária). Na segunda edição da "Expedição Floresta", os demais membros do Navisual não puderam participar, então obtivemos menos registros em vídeo. Consegui apenas algumas cenas que captei com o celular. Os dois primeiros eventos foram abertos a todos interessados e o número total de participantes ficou em torno de trinta. 
O terceiro evento foi a primeira edição do "Passeio das Artes", em caráter de teste do percurso, participei com uma câmera fotográfica e o gravador de som do celular para registro de pequenos relatos que foram feitos ao longo do percurso pelo bairro, estimulados por perguntas que eu realizava segundo um roteiro semiestruturado, conforme Michelat (apud Thiollent, 1987). Este terceiro evento foi realizado para convidados, pois o organizador, Jorge Piqué, da UrbsNova, pretendia avaliar o trajeto planejado e o tempo necessário para percorrê-lo, previsto, incialmente para três horas. Este evento-teste contou com umas quinze pessoas e durou também pouco mais de três horas, como os outros.

\section{Performances de e em um território}

O bairro Floresta de Porto Alegre sofreu impactos com a desindustrialização. Antes era chamado de "bairro de chaminés" e abrigava muitos de seus funcionários com moradias coletivas, de acordo com Franco (1992), porém recebeu pouca atenção do poder público $^{3}$ e caiu no esquecimento, até que o advento da Copa do Mundo trouxesse esperanças de novas perspectivas, pois o bairro, apesar de não ser turístico, encontra-se em um lugar que seria estrategicamente bom para isso, entre o aeroporto e a rodoviária. Hoje, diversos atores estão presentes discutindo propostas de "revitalização". A prefeitura chegou a prometer resultados para "antes da Copa do Mundo de 2014"4. A intenção nesse artigo não é problematizar a noção de "revitalização urbana", nem provocar reflexões sobre os processos de gentrificação (Leite, 2007; Furtado, 2004) e de desequilíbrio e desigualdades sociais suscitadas pelas transformações urbanas (Santos, 2008), conforme propõem algumas pesquisas nesta área. Apresento uma definição utilizada pelo Centro de Estudos Territoriais, do Instituto Universitário de Lisboa. Para eles, revitalização urbana é:

um plano e processo de formulação estratégica urbanística com carácter inclusivo e integrador, capaz de provocar iniciativas, projectos e actuações - de carácter transversal e sectorial -, sendo um instrumento de gestão colectiva do território com

\footnotetext{
${ }^{3}$ De acordo com narrativas de moradores e agentes interessados no processo de revitalização urbana, durante saída de campo e discursos proferidos nas mídias virtuais, como se pode ver na comunidade da Associação Refloresta, no site de relacionamento Facebook.

${ }^{4}$ Matéria do blog "Porto Imagem": "Depois do glamour, o abandono do $4^{\circ}$ Distrito em Porto Alegre. Prefeitura promete revitalizar a área antes da Copa do Mundo de 2014". Acessado em: 02/10/2013. Disponível em: http://portoimagem.wordpress.com/2011/05/21/depois-do-glamour-o-abandonodo4\%C2\%BA-distrito-em-porto-alegre/
} 
capacidade para utilizar como recursos próprios, programas urbanos muito diferenciados, de cariz mais social, económico ou cultural. (CET, slide 4$)^{5}$

Por meio de pesquisas documentais, midiáticas e com interlocutores que interagi durante as saídas etnográficas, como moradores, trabalhadores, frequentadores e estudiosos do Quarto Distrito, foi possível perceber um discurso, em geral, positivo em relação à revitalização urbana, como uma razoável solução aos problemas. Estas preocupações estão geralmente ligadas à perturbação sonora noturna e à falta de eficiência na coleta de lixo, na iluminação pública, na segurança e na preservação dos patrimônios imobiliários ${ }^{6}$. Durante a noite, principalmente na Rua São Carlos, a presença da prostituição não é bem vista por todos. As maiores queixas são relativas ao barulho que produzem e à prática de nudez em frente às portas residenciais. Estes e outros depoimentos foram relatados em um evento organizado para tratar especificamente da questão da insegurança. Participei da primeira edição deste ano, que contou com a presença de representantes de várias entidades locais do comércio, de colégios, da brigada militar e de associações, além de síndicos, vereadores, moradores e trabalhadores do bairro Floresta. Foram expostos casos de violência, roubos, furtos e um sentimento de intranquilidade. A performance do Capitão Rohers, da Brigada Militar, parecia de acordo o objetivo da reunião, pois ele escutou todos os relatos, fez apontamentos e, no final, anunciou que tomaria as providências necessárias e poderia ser cobrado no encontro seguinte. Nos bairros vizinhos, também pertencentes ao Quarto Distrito, as maiores reclamações estão relacionadas aos alagamentos pluviais e ao medo gerado pelas ocupações dos espaços vazios ou de fábricas e galpões considerados "abandonados".

Em contrapartida, existem também aqueles que se posicionam contra a "revitalização urbana", alegando receio de especulação imobiliária e transformação estética do bairro (arquitetônica e social), conforme pronunciou um morador do bairro

\footnotetext{
${ }^{5}$ CET - Centro de Estudos Territoriais do Instituto Universitário de Lisboa, Políticas Públicas de Revitalização Urbana - Reflexões para a formulação estratégica e operacional das actuações a concretizar no QREN. Apresentação em Power Point, Lisboa.

Disponível em: www.qca.pt/fundos/download/conf_ppt/12_Revitalizacao_Urbana .pps. Acessado em: 01/10/2013.

${ }^{6}$ Algumas das referências podem ser lidas nas seguintes matérias e artigos: Blog Porto Imagem, já referida anteriormente; ClickRBS - "Moradores e empresários se unem para revigorar o bairro Floresta". Disponível em: http://zh.clicrbs.com.br/rs/porto-alegre/noticia/2014/05/moradores-e-empresarios-seunem-para-revigorar-o-bairro-floresta-4506076.html Acessado em: 30/05/14; Correio do Povo. Moradores são reféns do medo.

Disponível em: http://www.correiodopovo.com.br/Noticias/?Noticia=296174. Acessado em: 02/10/2013.
} 
Floresta, durante o evento "Urbanismo Orgânico", organizado por um dos grandes apoiadores e articuladores no processo de revitalização, o Porto Alegre CITE, no espaço Nós Coworking. Neste espaço, a professora de arquitetura da PUC-RS, Dra. Leila Nesralla Mattar, apresentou sua pesquisa desenvolvida no Quarto Distrito sobre as proximidades entre arquitetura e relações humanas, trazendo fatos históricos, econômicos, sociais e de planejamento urbano que contribuíram para a atual configuração e situação da região. Segundo ela, as formas de sociabilidade praticadas antigamente na região teriam sido afetadas com a extinção de clubes, creches, associações, cinemas, espaços de lazer e de confraternização. Outrossim, a história da degradação e as alterações arquitetônicas, começam a mudar a identidade visual, cultural e social da região ${ }^{7}$. Contudo, alerta Mattar durante o evento que ainda é possível preservar o que está em boas condições, buscando realçar suas potencialidades, sem precisar levantar prédios altos e novos que descaracterizem esteticamente a área (em amplos sentidos). Em sua apresentação, a professora utilizou-se de um conjunto significativo de imagens e mapas que não apenas situavam o espectador, mas também tinham o propósito de comparar as transformações urbanas sucedidas e sensibilizar o grupo presente quanto à existência e necessidade de preservar as características da área ${ }^{8}$. As imagens projetadas cruzaram com um imaginário urbano criado pelas experiências e memórias vividas, reorganizando as construções mentais coletivas e individuais dos presentes ao evento.

\begin{abstract}
Para que se compreenda a estética urbana no Brasil é fundamental que se percorra a construção de uma duração na memória coletiva da sociedade brasileira, segundo a qual a não-racionalidade aparente da paisagem urbana do país pode ser vista como tributária desta adesão coletiva e irrestrita de seus habitantes à ordem "sensível" e "afetual" que se desprende do teatro da vida coletiva das cidades brasileiras, "estetização" da vida quotidiana como forma última de desafiar a dispersão e o aniquilamento existencial de seu corpo social (Eckert e Rocha, 2013a: 238).
\end{abstract}

\footnotetext{
${ }^{7}$ Nesta última década, começaram a surgir edifícios altos, espelhados e incorporadoras imobiliárias fazem muita pressão na região para comprar um conjunto de casas antigas próximas, com intuito de colocar em prática projetos já existentes de edificações verticais altas que destoariam, segundo Mattar, da estética particular do local.

${ }^{8}$ Em sua tese de doutorado, defendida no PPGH/PUCRS, Mattar afirma: "Em Porto Alegre, na paisagem de prósperos armazéns atacadistas e fábricas, inseriam-se casas, sobrados e outros usos que integraram o quadro diverso que constituía o lugar. Desde o início do século XX, sua importância aumentou, à medida em que foi cenário de importantes transformações sociais e econômicas da cidade que se industrializava e de uma sociedade que almejava modernizar-se. No contexto geral da capital, adquiriu uma identidade própria, que o diferenciava de outras áreas" (Mattar, 2010: 18).
} 
O imaginário social do Quarto Distrito é constantemente reconfigurado e redesenhado por novos traçados, novas redes e conexões. Assim, o público podia deslocar-se autonomamente pelo mapa mental ou, se não possuísse tais referenciais, apoiar-se nas indicações pictóricas para acompanhar os trajetos performáticos dos bairros em questão. Por meio das narrativas visuais, textuais e orais, o distrito enquanto conceito arbitrário passa a ser apresentado, legitimado enquanto espaço constituído por meio de formas concretas e palpáveis, cores, linhas, figuras humanas e não-humanas. Os enquadramentos e escolhas estéticas visuais realçam as propostas dos fotógrafos e da palestrante, enquanto agenciadores da informação. As histórias e as memórias se reciclam, ganham novos olhares e novos usos.

Com relação às imagens apresentadas no evento e as narrativas de Mattar, pudemos aferir que as performances sensíveis e afetivas das relações sociais foram - e ainda são - modificadas pela série de barreiras arquitetônicas urbanas que o poder público criou no Quatro Distrito. Como exemplos trazidos pela palestrante, existe a construção da avenida Farrapos, que acabou dividindo a região em duas áreas; o aterro junto ao Rio Guaíba e, posteriormente, a elevação da Castelo Branco, que isolou esta região do convívio com o Rio; o Viaduto da Conceição que, por sua vez, dividiu ao meio a avenida Voluntários da Pátria (avenida esta que hospedava as mais importantes lojas de comércio e indústrias e as conectava com a cidade); e os viadutos da avenida Sertório, que isolaram a outra margem do Rio Guaíba e a Igreja dos Navegantes.

Após a Constituição de 1988, a cidade foi dividida em zonas e o bairro Floresta começou a fazer parte do "Quarto Distrito", segundo Alexandre Fortes (2004). Essas configurações de bairro, zona e distrito são arbitrárias. Dentro do "Quarto Distrito" há outros bairros com características bem diferenciadas, que devem ser levadas em conta para a tomada de decisões quanto a "revitalização da área", pois cada bairro e região possui suas necessidades próprias. A agência de inovação social UrbsNova, utiliza o conceito de "Distrito Criativo", também empregado em outras cidades do mundo, como no Rio de Janeiro, Barcelona, Nova Iorque e Cidade do Cabo. Torna-se cada vez mais forte a associação do "Quatro Distrito" como um "Distrito Criativo", graças às atividades realizadas por diversos atores e pelas imagens que circulam na internet. É neste contexto que os eventos exploratórios pelo bairro foram criados. Durante o "Passeio das Artes", um participante questionou Piqué sobre a diferença entre essa atividade e o "Free Walking Poa" (atividade que também percorre ruas de Porto Alegre, 
mas é organizado por outro grupo). Piqué esclareceu sobre a importância de tais eventos como estratégia de visibilidade para o processo de associação do bairro ao projeto:

É que o Distrito Criativo é um grupo de artistas e empreendedores de economia criativa. O Free Walking Poa é um passeio que se faz pelos bairros. O que a gente quer é integração desse pessoal que vive e trabalha aqui. Então é mais difícil de desenvolver. No início, quando a gente fez, era um pouco assim, era um passeio [fazendo alusão às Expedições Floresta I e II]. Agora é mais do que um passeio, é um território que a gente quer criar, dar identidade, quer resgatar o passado, a gente tem todo esse trabalho de visitar moradores antigos, sabe? Aqui pertinho mesmo tinha um armeiro que tem 80 e tantos anos. Então, tem essa história. Não é simplesmente um passeio turístico. É um projeto econômico e social, que tem passeio porque é legal fazer passeios para mostrar para as pessoas. Mas o passeio é só uma vitrine, o que tá dentro é o território.

Explorar um território, e não apenas um bairro, é extrapolar suas fronteiras, suas ruas e limitações. Trata-se de um lugar de confluências, de interações e organizações sociais, de resistências, relações econômicas e afetivas. Um território é um espaço de pluralidade, de fluxos contínuos, trocas simbólicas, possibilidades de sociabilidade ou de recolhimento, formações de novas narrativas e expectativas, luta pelo reconhecimento de seus direitos e de suas identidades. Pensar um território em processo de "revitalização urbana" é conferi-lhe um status de decadência e falência, desconsiderando a existência de toda a dinamicidade e vitalidade de um espaço complexo. Trata-se, antes, de pensar em um tempo e espaço de interação e produção de transformações na cidade, visando o consumo ideológico, cultural, político e econômico de "valorização" do território. Trata-se de um processo de performances de inovação e criatividade.

Nesse contexto, a agência de inovação social UrbsNova pretende, dentre outros objetivos, "planejar, produzir, divulgar eventos que por sua natureza inovadora impliquem em um real benefício a comunidade mais ampla", segundo consta em sua página na Internet ${ }^{9}$. A agência criou os eventos "Expedição Floresta I e II"10 e o projeto do "Distrito Criativo" que envolve o "Passeio das Artes" 11 como ação estratégica. A

\footnotetext{
${ }^{9}$ http://urbsnova.wordpress.com

10 Para mais detalhes sobre a "Expedição Floresta I": Disponível em: http://urbsnova.wordpress.com/expedicaofloresta/ Acessado em: 16 de maio de 2014. "Expedição Floresta II": Disponível em: http://urbsnova.wordpress.com/expedicaofloresta2/ Acessado em: 16 de maio de 2014.

${ }^{11}$ Vendo o potencial cultural do evento e dentro da perspectiva conceitual de "Distrito Criativo, surge, então o "Passeio das Artes": Disponível em: http://distritocriativo.wordpress.com/passeio-das-artes/ Acessado em: 16/ de maio de 2014.
} 
partir de um mapeamento inicial, a agência faz os contatos com as pessoas e os estabelecimentos de interesse, estipula um roteiro prévio, abre as inscrições via internet, divulga o evento pelas mídias sociais e realiza o itinerário com os interessados. A turma que se forma é heterogênea em relação às ocupações (artistas, arquitetos, fotógrafos, economistas, empresários, designers, comunicólogos, advogados) e idades (jovens, adultos e idosos). Entretanto, a maioria aparenta um alto nível de escolaridade e condições financeiras. Alguns moram no bairro ou nas proximidades, e outros se deslocam de mais longe, curiosos pelos eventos.

\section{Expedição Floresta 1}

\section{Método}

reunir pessoas envolvidas com o projeto para fazer uma caminhada e encontrar com quem mora e trabalha no local para conhecer seus projetos e trocar informações.

A ideia desse projeto surgiu nas reuniões sobre o 4. ${ }^{\circ}$ Distrito, realizadas em 2013 pelo Nós Coworking, do Shopping Total, coordenadas por Walker Massa.

\section{Objetivo final}

a partir desse primeiro contato, dar condições para que pessoas do bairro ou de fora proponham eventos, intervenções e ações específicas colaborativas sobre a área visitada.

\section{Público-alvo}

- participantes das reuniões sobre o

Quarto Distrito no Nós coworking, moradores membros da Associação Refloresta, pessoas interessadas na revitalização do Floresta e do Quarto Distrito

\section{Expedição Floresta 2}

\section{Método}

reunir pessoas interessadas no bairro para fazer uma caminhada e encontrar com quem mora e trabalha no local, conhecer seus projetos e trocar informações.

Não se trata exatamente de um passeio cultural. Há um aspecto cultural na caminhada, mas queremos principalmente conhecer o que existe, para revitalizar a área, especialmente apoiando a presença de economia criativa.

\section{Objetivo final}

a partir desse primeiro contato, dar condições a criação de um projeto geral de recuperação urbana e reconversão econômica, através de eventos, intervenções e ações específicas colaborativas sobre a área visitada.

\section{Público-alvo}

moradores do bairro e membros da Associação Refloresta,

- pessoas interessadas na revitalização do Floresta e do Quarto Distrito

\section{Passeio das Artes}

"Dentro da economia criativa, no Distrito C, são em maior número os artistas e empreendedores que trabalham com artes visuais e 15 locais estão abertos ao público, como ateliers de artista, galerias de arte, antiquários e brechós. Por isso criamos o Passeio das Artes como um circuito sugerido, a pé ou de bicicleta, para que os porto-alegrenses e os visitantes de outras cidades e países possam descobrir e visitar essa parte do Distrito Criativo. O circuito sugerido não tem início ou fim, cada visitante escolhe onde começar e onde terminar. Fazem parte também do circuito 7 locais de gastronomia que participam do Distrito C por sua qualidade, como cafeterias, padarias, bares e restaurantes, onde o visitante poderá fazer uma pausa durante o trajeto. 
Por sua importância histórica e artística incluímos no trajeto o patrimônio histórico edificado, que está indicado pelos pontos vermelhos no mapa acima. Periodicamente levamos grupos de pessoas para percorrer partes do trajeto sugerido, especialmente nos sábados pela manhã. Esses percursos guiados são gratuitos".

A partir dos sites da "UrbsNova" e do "Distrito Criativo", organizei as informações em quadros comparativos, grifando algumas partes que contribuem para refletir sobre as transformações que os eventos passaram. Quanto aos métodos, objetivos e públicos-alvo das Expedições Floresta, percebo que a primeira edição estava mais direcionada àqueles que já estavam de alguma forma envolvidos com projetos de revitalização urbana e que podiam, como consta no objetivo do evento, propor ações e usar do momento como vitrine de seus projetos. Neste caso, o público participante se mostra ativo e dividindo da mesma forma a responsabilidade pela revitalização da área. A segunda edição, ainda com caráter exploratório, mudou um pouco a configuração, tornando-se mais abrangente e aberta, pois almejou reunir pessoas "interessadas no bairro", não necessariamente já "envolvidas" e que colaborassem no objetivo de criar um "projeto geral de recuperação urbana e reconversão econômica". O Passeio das Artes, contudo, é uma ação que teve a edição teste, a qual participei, mas que se ambiciona permanente e aberta a todos, envolvidos ou não, interessados ou não, no projeto de revitalização. Para percorrer o itinerário sugerido, o "visitante" pode escolher por onde começar e terminar, e se vai percorrer a pé ou de bicicleta - como sugerido pelo site - , tendo total liberdade.

Considerando as diferenças nas propostas dos eventos, chamou atenção que os participantes do "Expedição Floresta I" já possuíam, em grande parte, algum tipo de negócio ou de pesquisa no/sobre o bairro. O organizador e guia, Jorge Piqué, conduzia o grupo pelos vários pontos pré-determinados e todos paravam para escutar as histórias e interagiam trocando suas impressões. Com esta mesma metodologia, a "Expedição Floresta II" percorreu alguns lugares já conhecidos pelo evento anterior e passou por outros novos. O roteiro deu mais destaque aos espaços voltados à arte, com maior número de galerias e antiquários. Esta edição, porém, contou com menos participantes. O clima entre as pessoas foi muito prazeroso e descontraído. Nem o chuvisco atrapalhou o passeio. Um momento de destaque foram as histórias do Sr. Edison Karam, 83 anos, proprietário da oficina especializada em manutenção e conserto de armas. Ele 
contou sobre as mudanças do bairro, da rua e da cultura local. Segundo ele, antigamente fazia parte da cultura gaúcha o porte de armas. Suas narrativas também tiveram um tom de despedida, pois um tempo depois, ele fechou o estabelecimento, em decorrência do falecimento de seu irmão mais novo e da inviabilidade de continuar o trabalho frente às novas leis que regulam a posse de armas. Jorge Piqué, sensibilizado pela conservação da memória social, econômica e cultural, realizou um vídeo entrevistando o Sr. Karam.

Algumas empresas fecham e, ao mesmo tempo, outras portam se abrem. O estímulo, pelo plano do Distrito Criativo é incentivar a economia criativa na região, divulgando, portanto, esses fluxos imobiliários e concedendo benefícios para empreendimentos ligados a processos criativos. Viu-se fechar também as portas da Celare, um estabelecimento gastronômico que durou pouco tempo. Os proprietários pareciam empolgados com o negócio quando passamos lá na primeira vez, mas, segundo Piqué, esperavam retorno financeiro rápido e com o pouco movimento, acabaram desistindo. Como já comentei acima, o brechó de rua "Solte suas roupas ao vento", resolveu diminuir a periodicidade das atividades. Entretanto, ainda há muitos estímulos para que os projetos continuem e se renovem. É o caso do "Passeio das Artes". A primeira edição foi em caráter de teste e contou com aproximadamente uma quinzena de pessoas, a maioria artistas, fotógrafos amadores, arquitetos e advogados. Um público selecionado pelo organizador para que opinassem sobre o trajeto e o tempo de percurso. Visitamos principalmente espaços de arte e gastronomia.

Nesta saída, minha performance enquanto pesquisadora foi diferente, considerando as experiências passadas e uma vigilância maior aos conceitos de sociabilidade e narrativa que norteavam a pesquisa nos momentos de registro imagético. Quanto ao corpo e a vestimenta em campo, ative previamente a peças que traziam mais praticidade, colocando estrategicamente no bolso de fora da mochila uma caderneta e uma caneta para fácil acesso, uma calça com bolso para manuseio do aparelho de registro audiovisual e uma câmera fotográfica pendurada no pescoço. Cada movimento, cada ação, cada postura em campo altera a performance da pesquisa, e, ainda, os resultados que ela produz. Alerta Zumthor (2007: 102), que "a performance, de qualquer jeito, modifica o conhecimento. Ela não é simplesmente um meio de comunicação: comunicando, ela o marca" (ibidem: 29).

Portanto, nesse processo de comunicação, a performance é uma prática de regras, códigos sociais e competências do saber-fazer que concretizam em um horizonte de 
significados uma mensagem ou uma informação (ibidem). O espaço físico performatiza sua dinamicidade, as pessoas contam suas histórias, o guia conduz, as câmeras fotográficas à postos e tudo contribui para a formação do imaginário urbano da região. Juntam-se aí as fotografias antigas da cidade que emolduram as paredes de alguns estabelecimentos, como na padaria Dalmás e no Porto Alegre Hostel Boutique. Um conjunto de imagens (fixas e mentais, segundo Kossoy, 2002) se entrelaçam e produzem novos sentidos, memórias, imaginários, realidades e narrativas. Vê-se um misto de memórias do passado e perspectivas futuras. $\mathrm{O}$ próprio percurso se mostra como um processo estético. Para Eckert e Rocha, a "estética do 'sensível', na memória coletiva da sociedade brasileira, rende homenagem a uma dialética da duração construída por uma coletividade já habituada a sofrer contínuos processos de desenraizamentos de seus territórios de origem" (2013a: 238). As constantes mudanças urbanas e surgem narrativas de um passado nostálgico. Antigamente, o Quarto Distrito se caracterizava por ser um polo industrial, com clubes sociais e esportivos, localizados próximos ao rio Guaíba. Contudo, as relações de trabalho, de moradia e de lazer foram alteradas com o crescimento da cidade e a saída dessas empresas para as zonas periféricas, conforme relata Leila Mattar (2010). Hoje, o acesso ao rio não existe mais, as formas de sociabilidade são outras, as práticas econômicas e a paisagem do bairro também sofreram transformações.

Percebemos no contexto da etnografia da duração (Eckert e Rocha, 2013a), que os tempos e as memórias do passado, do presente e do futuro se mesclam durante os passeios pelo bairro, convergindo em um momento único uma rica variedade de símbolos e ritualizam as transições e confluências sociais e culturais. A heterogeneidade do grupo se percebe nas diferentes performances desempenhadas pelos participantes. Há os que se interessam mais pelas histórias contadas sobre os estabelecimentos, os curiosos para saber dos preços e produtos nas lojas, os que buscam aumentar seu networking, os que querem conhecer melhor o bairro, os que querem abrir ou apresentar seus negócios e os que apenas querem passear e conhecer novas pessoas.

Há também aqueles que querem aproveitar o sábado para fotografar, explorar o espaço e estão mais interessados na potencialidade das histórias visuais do que as orais. Como o "Passeio das Artes" tem um propósito mais cultural do que as "Expedições Floresta", ele reuniu, na primeira edição, mais artistas e fotógrafos que buscavam recriar em imagens os cantos, os momentos e as cores de forma bem poética. O próprio evento 
se mostra como um processo estético e ritual. E é possível perceber diferentes performances entre aqueles que registram e os que não registram imagens. Uma delas é o descompasso de ritmo, pois os fotógrafos queixam-se da velocidade acelerada para percorrer o trajeto. O tempo para as imagens é outro, é o do olhar atento, da contemplação de minúcias, das descobertas e da criação. Tanto no momento da captura da imagem, quanto de sua recepção, "é preciso estar presente, presente à imagem no minuto da imagem: se houver uma filosofia da poesia, essa filosofia deve nascer e renascer no momento em que surgir um verso dominante, na adesão total a uma imagem isolada, no êxtase da novidade da imagem" (Bachelard, 2000: 183).

Adentramos a poética do espaço pela etnografia visual e apreendemos as transformações urbanas do bairro Floresta e suas performances enquanto espaço urbano. As performances orais fundem-se às visuais e formam novas realidades e percepções. Esta ressignificação estimula a disseminação de reflexões sobre os projetos e sobre o espaço urbano. Cada participante produz uma coleção de imagens que compartilha pelas redes sociais na Internet e colabora para construção imagética do "território criativo".

Cada fotografia deverá ter alguma importância quando 'lida' individualmente e, ao mesmo tempo, deverá servir como parte integrante de uma sequência de fotografias que no seu conjunto possam vir a compor uma das formas de antropologicamente narrar o que é singular (Achutti, 1997: 69).

A força das imagens se mostra nos momentos ritualísticos de consagração, segundo noção de Pierre Bourdieu (1996). Marcamos o início e/ou encerramento de um evento com fotografias. Elas servem como uma espécie de documento que garante sua realização, além de ser um especial tesouro de memórias. No último "Passeio das Artes" que participei, a "fotografia de consagração", em que o grupo todo se reunia para registrar o momento, não aconteceu apenas no início ou no final do evento, e sim, em frente a cada estabelecimento visitado. Os eventos realizados em prol da revitalização urbana do Quatro Distrito, em Porto Alegre, permitem uma renovação na forma de se relacionar com os espaços. Ao mesmo tempo em que se escutam relatos, o grupo participante forma novas histórias e interage entre si, intercambiando opiniões, memórias e visões de mundo. Os eventos aproximam pessoas, ideias e produzem um momento ímpar. Trata-se de uma possibilidade de sociabilidade no bairro, que, junto com a cultura visual, contribuem para legitimação e credibilidade dos projetos em questão. 


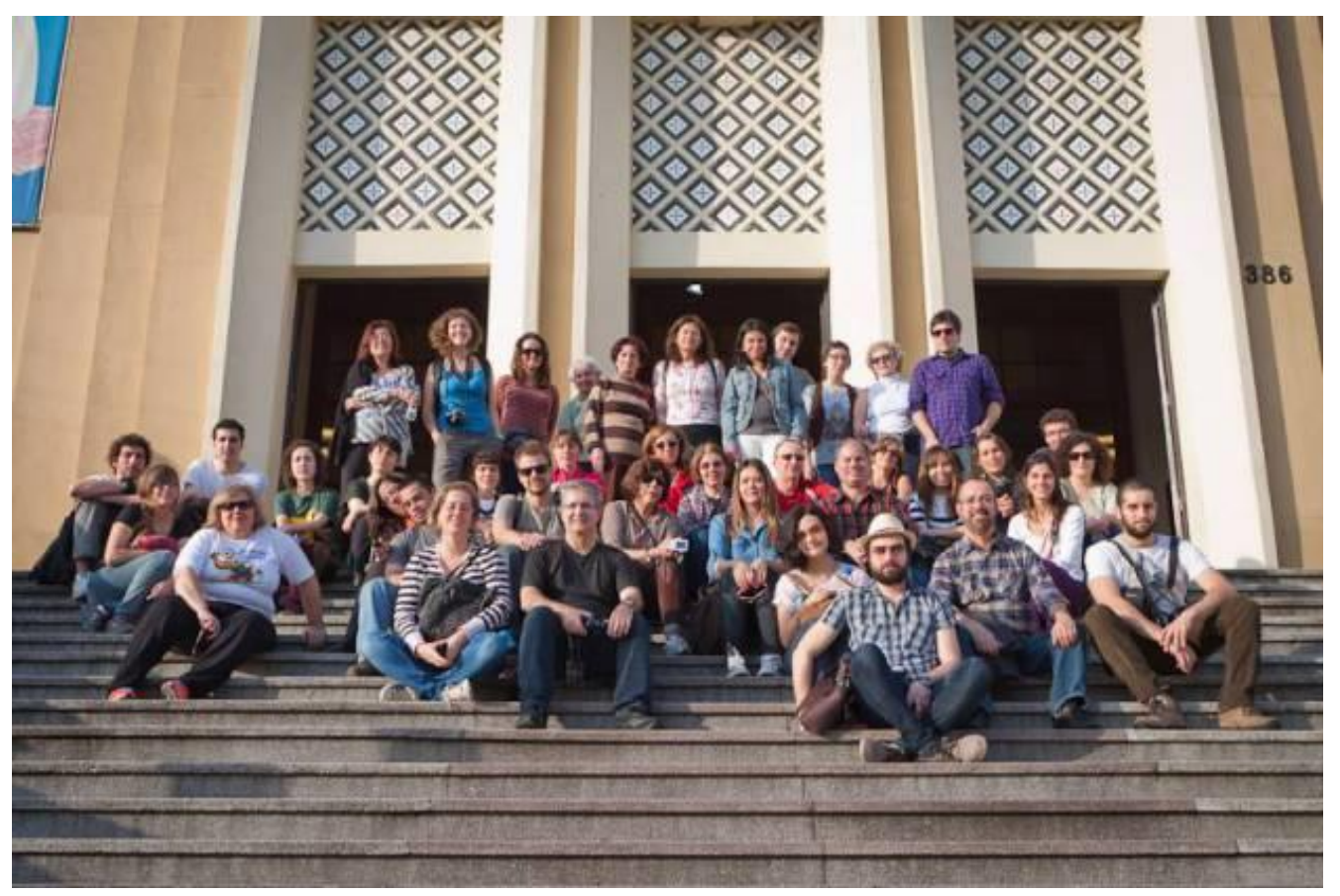

Grupo em frente à Igreja Santa Terezinha, ao final da Expedição Floresta I. Foto: Fabricio Barreto

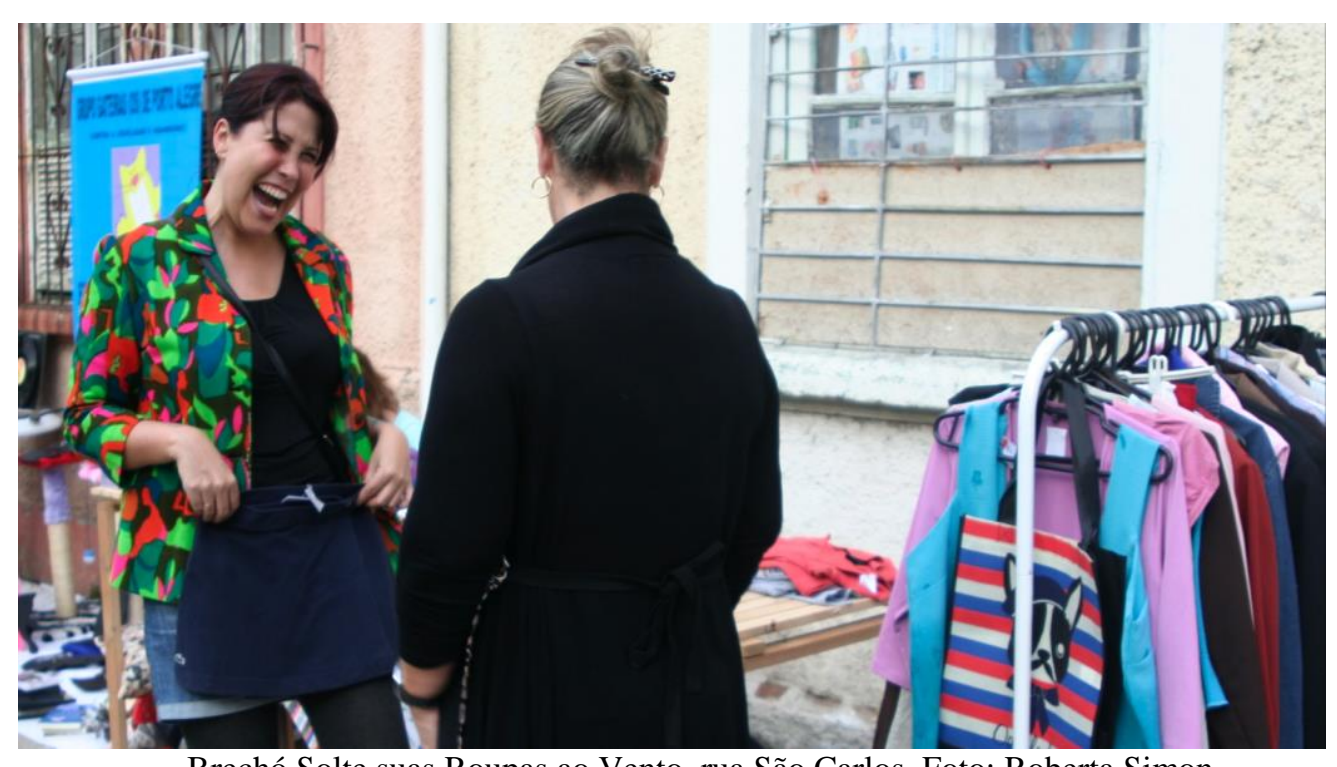

Brechó Solte suas Roupas ao Vento, rua São Carlos. Foto: Roberta Simon

As três imagens a seguir foram realizadas durante a edição teste do "Passeio das Artes", ocorrido em maio de 2014. 


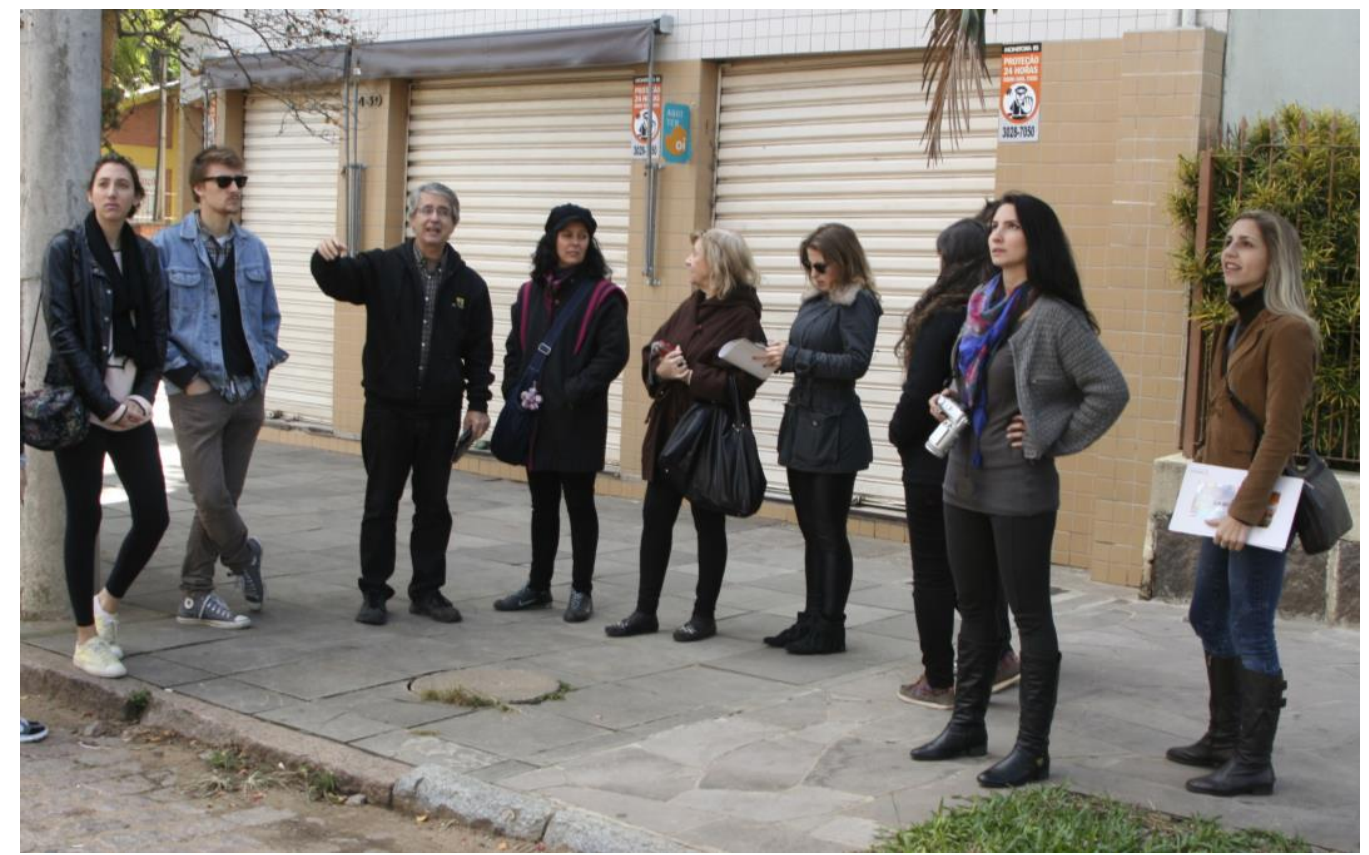

O organizador do evento Jorge Piqué conta aos participantes, histórias do bairro. Foto: Roberta Simon.

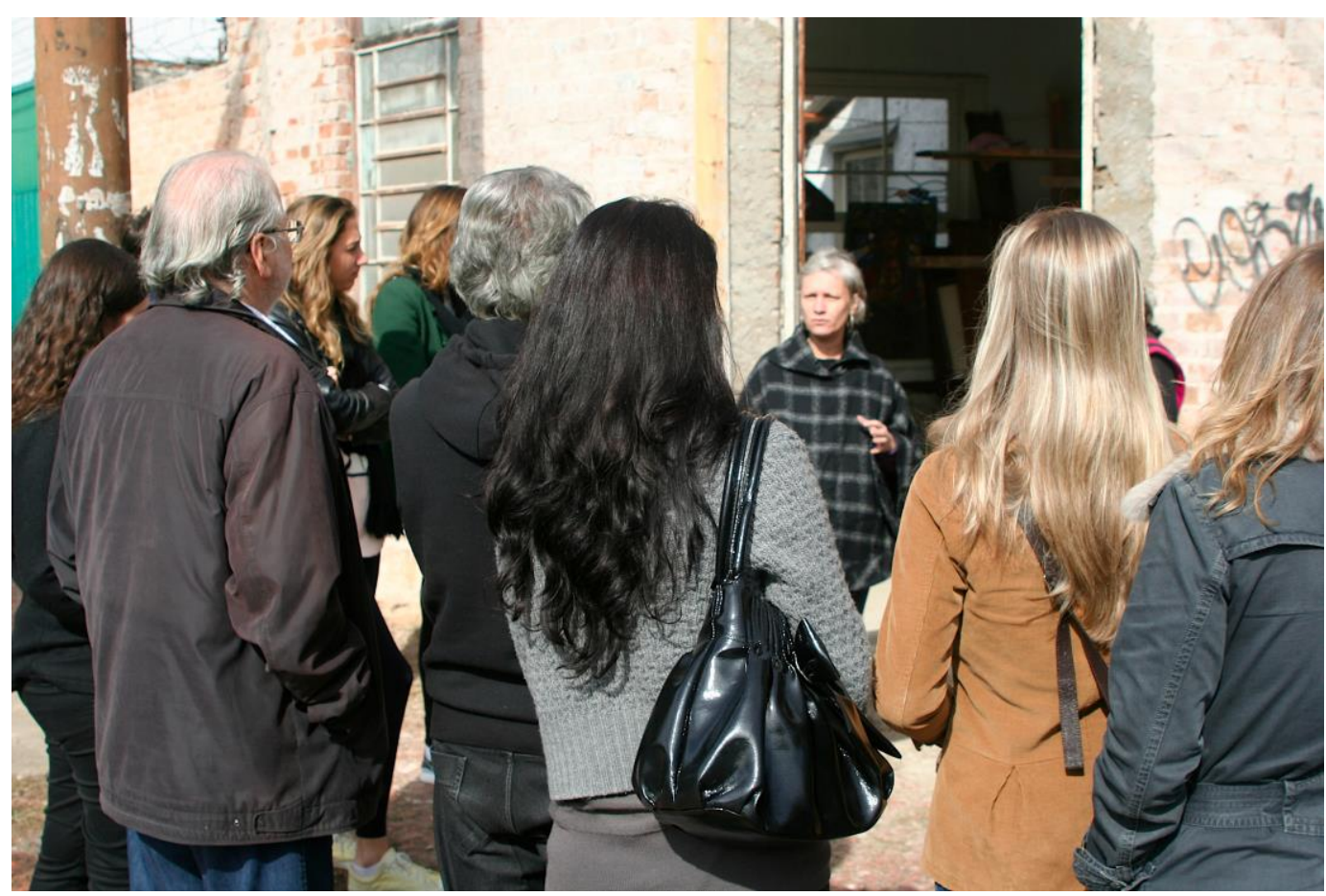

A artista plástica Mariana apresenta o processo de transformação de seu ateliê em loja de arte. Foto: Roberta Simon. 


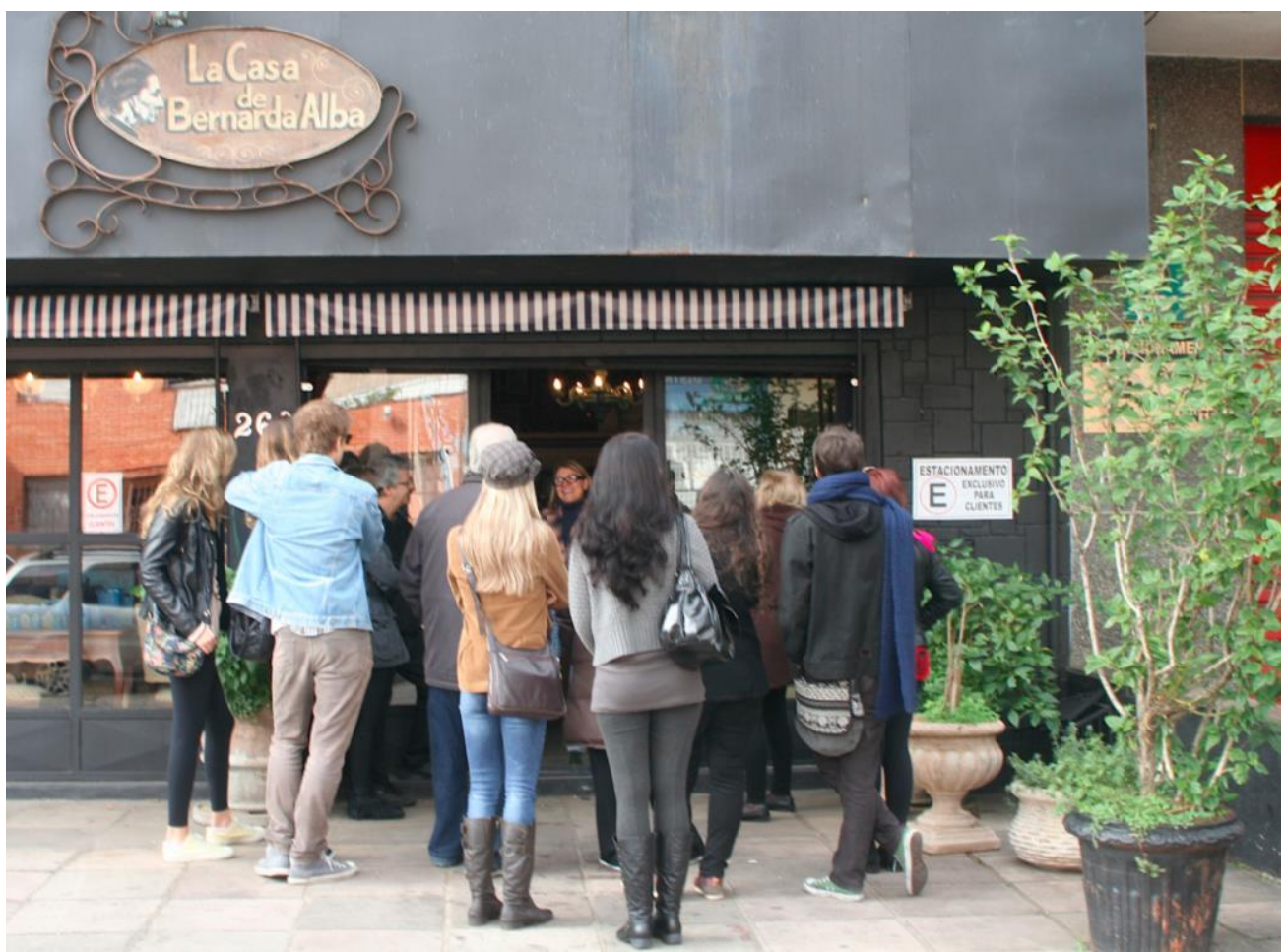

A proprietária da La Casa de Bernardo Alba apresenta o antiquário e fala sobre o "Distrito Criativo". Foto: Roberta Simon.

\section{Referências}

ACHUTTI, Luiz Eduardo Robinson. Fotografia: mediação, técnica e narração. IN:

Fotoetnografia. Um estudo de antropologia visual sobre o cotidiano, lixo e trabalho. Porto Alegre: Tomo Editorial; Palmarinca. 1997. p. 51-81.

ARANTES. Otília Beatriz F. Uma estratégia fatal - a cultura nas novas gestões urbanas. In: Otília Arantes, Carlos Vainer e Hermínia Maricato. A cidade do pensamento único: desmanchando consensos. Petrópolis, Rio de Janeiro, Vozes, 2000, pp. 11 a 74.

BACHELARD, Gaston. A dialética da duração SP, Ática, 1988.

. A formação do espírito científico: contribuição para uma psicanálise do conhecimento. Rio de Janeiro: Contraponto, 1996.

. A Poética do Espaço. São Paulo: Editora Ática, 2000. Coleção Os Pensadores.

BOURDIEU, P. Razões Práticas. Campinas: Papirus: 1996.

CONORD, Sylvaine. A função mediadora da imagem fotográfica. In: Revista Iluminuras. V. 14, n. 32. 2013. ISSN 1984-1191. p. 11-29.

DE CERTEAU, M. de. A Invenção do Cotidiano. Artes de fazer. Rio de Janeiro: Vozes, 1994.

ECKERT, Cornelia; ROCHA, Ana Luiza Carvalho da. Etnografia da Duração: antropologia das memórias coletivas em coleções etnográficas. Porto Alegre, Marcavisual, 2013a. 
Etnografia de rua: estudos de antropologia urbana. Porto Alegre: Editora da UFRGS, $2013 b$.

FORTES, Alexandre. Nós do Quarto Distrito...: a classe trabalhadora portoalegrense e a Era Vargas. Caxias do Sul, RS: Educs; Rio de janeiro: Garamond, 2004.

FRANCO, Sérgio da Costa. Porto Alegre: Guia Histórico. $2^{\circ}$ edição. Porto Alegre: Ed. Universidade/UFRGS, 1992: 163-167.

FURTADO, Carlos Ribeiro. Gentrificação e (re)organização urbana no Brasil: o caso de Porto Alegre (1965-1995). 2004. Tese de Doutorado - Instituto de Filosofia e Ciências Humanas, Universidade Federal do Rio Grande do Sul, Porto Alegre, 2004.

KOSSOY, Boris. Realidades e ficções na trama fotográfica. 3.ed. Cotia: Ateliê Editorial, 2002. LEITE, Rogério Proença. Contra-usos da cidade. Lugares e espaços públicos na experiência contemporânea. Campinas: Ed. UNICAMP, 2007.

LIPKAU, Elisa. La tercera mirada: representación y performance. Dimensión Antropológica, Año 14, vol. 39, enero/abril, 2007.

MATTAR, Leila Nesralla. A modernidade em Porto Alegre: arquitetura e espaços urbanos plurifuncionais em área do 4o. Distrito. Tese de doutorado. Faculdade de Filosofia e Ciências Humanas, Pós-Graduação em História, PUCRS, Porto Alegre, 2010.

MICHELAT, Guy. Sobre a utilização da entrevista não-diretiva em sociologia. In THIOLLENT, Michel(org). Crítica metodológica, investigação social e enquete operária. Rio: Polis, 1987.

REINHARDT, Bruno Mafra Ney. Da Lição de escritura. Horizontes Antropológicos, Porto Alegre, ano 10, n. 22: 233-254, jul./dez. 2004.

SANTOS, Milton. A Natureza do Espaço: Técnica e Tempo; Razão e Emoção. $4^{\mathrm{a}}$ edição, $4^{\mathrm{a}}$ reimpressão. São Paulo: Editora da Universidade de São Paulo (Coleção Milton Santos; 1), 2008.

TURNER, Victor. Liminaridade e communitas - modelo e processo. In: O Processo Ritual. Petrópolis, Vozes, 1974: 116-59.

VELHO, Gilberto. Observando o Familiar. In: NUNES, Edson de Oliveira (Org). A aventura sociológica. Rio de Janeiro, Zahar, 1978. P. 36 a 46.

ZUMTHOR, Paul. Performance, recepção e leitura. São Paulo, Cosac \& Naif, 2007.

Recebido em: 13/09/2014

Aprovado em: 12/11/2014 